\title{
Performance Analysis of Wheeling Charges Determination Using Bialek's Tracing Method Employing With IPFC Controller in Deregulated Environment
}

\author{
P. Vidhya ${ }^{1}$ R. Ashok Kumar ${ }^{2}$ K. Asokan ${ }^{3}$ \\ ${ }^{1}$ Assistant Professor, Department of Electrical Engineering Annamalai University \\ ${ }^{2}$ Professor, Department of Electrical Engineering Annamalai University \\ ${ }^{3}$ Assistant Professor, Department of Electrical Engineering Annamalai University
}

\begin{abstract}
Transmission of electricity across the systems creates an essential link between the producers and consumers of the deregulated power sector. Transmission charges signify a minor proportion of overall operational expenses in utilities in the open market and transmission pricing need to be a reasonable and cost effective pointer used by the energy market for decision making, system enlargement and reinforcement of the system. The wheeling cost can be decreased by reducing power loss via incorporating proper FACTS devices in the system. In this scenario, tracing the flow of electricity has been gaining much more importance and its solution helps in evaluating a fair and transparent tariff. In this article, an attempt has been made to introduce a new flow based Bialek's tracing method to calculate the wheeling charge involving with optimal placement of recent FACTS devices of IPFC controller. The proposed approach has been tested on standard IEEE 30 bus system to prove the effectiveness of the proposed methodology. The simulation results are also compared with that of conventional method and with/without IPFC devices.
\end{abstract}

Keywords: Deregulation, Transmission pricing, Wheeling charges, Bialek's Tracing method, FACTS, IPFC controller

\section{Introduction}

During the nineties, many electric utilities around the world are dealing with deregulation, restructuring, privatization and create introduction of competition in the electric power industry. These worldwide power industry reforms are forced to increase of electrical energy production, transportation and distribution to offer a lower price with higher quality and more secure production to customers.

In the restructured power system, the transmission network system is a key mechanism for generators to compete in supplying large users and distribution companies. In a competitive deregulated environment, defining a pricing scheme is needed for transmission services which could meet revenue expectations, support efficient operation of electricity markets, encourage investment in optimal location of generation and transmission lines and adequately reimburse owners of transmission assets and also to reduce the effects of transmission monopoly [1].

The wheeling of transmission services (electrical energy) is the one of the most important prevalent of such unbundled services [2]. Therefore, in the deregulated environment, pricing of transmission services occupies a vital role in determining whether providing transmission services are economically viable to both the wheeling consumers and wheeling utility.

In a monopoly power industry, there are many methods have been proposed to evaluate the cost of transmission services. They are categorized into three types of cost: embedded cost, marginal cost and incremental cost. The cost which is based on the actual network usage of a transaction and are addressed as embedded cost (e.g., postage stamp, contract path, MW-mile method, MVA-mile method, Distribution factors method and Tracing methods), while others ( marginal/ incremental) method, which is based on the additional transaction cost that is caused by a specific electricity transaction. Examples of these methods are: Short -run marginal cost (SRMC), Long-run marginal cost (LRMC) and Short-run Incremental cost (SRIC) and long-run incremental cost (LRIC). From this aforementioned method, embedded cost method is the basic method of transmission pricing [3]. The main aim of this method is to calculate the transmission service cost in a proper way to allocate it among the transmission users. In the Postage stamp method, the transmission charges are based on stamp rate on an average cost and the magnitude of the allocated power. This method is simple and easy to measure. Contract path method is another traditional method used by the power industry and the power flow is confined to flow along the artificial specified path [4].

Based on the calculation of the extent use of the transmission network MW -mile method, which is proposed to calculate the cost depends upon the magnitude, the path and the distance travelled by the transacted power [5]. Various modified MW-mile methodologies have been proposed by many researchers [6, 7]. 
MVA-mile method is an enhanced charging methodology over MW-miles, it has been recognized that the use of transmission resources is the best one for the measurement of real and reactive power and [8]. In this method, the power flow at each method caused by the generation / load pattern of each agent is based on the combination of real and reactive power flows.

Distribution factors is an sensitivity analysis method and it shows the relation between changes takes place in power injection in a particular bus and the power flow changes takes place in a particular line. There are three different ways to calculate the distribution factors methods: Generalized Shift Distribution Factors (GSDF), Generalized Generation Distribution Factors, Generalized Load Distribution Factors (GLDF) [9].

Topological Generation Distribution factors based Power flow tracing method was introduced by Bialek in the year 1996, in this method the assumptions is made for the nodal inflows are shared proportionally among the nodal outflows [10]. Another tracing method was proposed by kirschen in the year 1997, which is based on definitions for domains, commons and links [11]. Using this method, it is also possible to calculate equivalent transactions by minimizing the total MW-Km distance covered in the entire system.

The complete space of tracing can be modeled by considering equality and inequality constraints. The power flow tracing methods are tracing the power flow from a source and sink and vice-versa. It can be further sub classified as a proportionate tracing method and optimal tracing method [12].

A.J.Conejio et al.,[13] proposed a method to find the share of participants to transmission cost allocation by forming $Z_{\text {bus }}$ that makes generator-load use the lines electrically close to it. The $Z_{\text {bus }}$ formulation is based on mathematical behavior model which is based on circuit theory and relates the nodal currents to line power flows. In ref [14], the authors rationalized proportional sharing principle of cooperative game theory and information theory. They concluded that the shapely value validates the proportional sharing principle. Also the other way to trace the electricity from power flow tracing algorithms can be found in Extended Incidence Matrix (EIM) considering loop flows. In this methods the charges had been allocated to generators and loads in 50:50 ratios [15]. In 2010, Rao et al., [16] explained the Min-Max fair allocation criteria for transmission system usage allocation.

Marginal pricing of electricity has been employed in several electricity markets. The marginal network revenue for a transmission entity results from the spatial discrimination of spot prices also called LMPs due to transmission constraints and losses. The revenue of this method is also used for financing future transmission investments. However typical marginal revenues account for a little percentage of the total fixed cost which leads to be additional charges and these charges are calculate using an embedded pricing method [17].

In 1986, N.G.Hingorani invented the FACTS technology based on Thyristor operation techniques and gained a greatest interest during the last few years; due to the recent techniques in power electronics are added. FACTS devices are found to be effective controller to solving various power system steady state control problem such as voltage regulation, transfer capability enhancement and control of power flow and enhance the flexible operation of the system [18].

FACTS controllers are broadly categorized as series type controllers, shunt type controllers and combination of series - series and shunt-series type controllers. Examples of shunt controllers: Static Var compensator (SVC).Static synchronous compensator (STATCOM). Thyristor controlled series capacitor (TCSC) and Static Synchronous series compensator (SSSC) is comes under the series type group controllers. Interline power flow controller (IPFC) is the example of series-series type controller and Thyristor controlled phase shifting transformer (TCPST) and Unified power flow controller (UPFC) are belongs to shunt-series type controller [19].

In the available FACTS devices, Interline power flow controller (IPFC) is the latest generation FACTS devices used in the power system for management of power flow in multi-line transmission system. The IPFC has the capability to carry out an overall real and reactive power compensation of the total transmission system [20]. In ref [21], the authors employed the Line-by-Line method with TCSC controller to determine the wheeling cost and losses of real and reactive power in the restructured power system. Here IEEE 30bus test systems are considered, illustrating the performance of the proposed system.

In this article, a new flow based Bialek's tracing methodology has been introduced in allocation of wheeling cost for various transactions. The FACTS devices are introduced in order to harvest the technological benefits. The problem formulation is done in two parts. The first part includes the mathematical approach without considering FACTS devices and the second part includes the FACTS devices in the system. The proposed approach has been tested on standard IEEE 30 bus test system to illustrate the superior performance of the proposed system.

\subsection{Various categories of Transmission Transaction}

Generally, a transmission transaction means it refers to the transmission component of the service used by a power utility. For example it deals with a power purchase, power sale or a wheeling transaction. There are several types of transmission transaction involved in power industry [22]. They are listed as follows: 


\subsubsection{Firm Transmission Transactions:}

A firm transmission transaction is defined as the result based on contractual arrangements between the utility and wheeling customers. A firm power wheeling is also called as reserved transactions because it makes reservation of capacity on transmission facilities to meet the needed transactions. These transactions are not involved to discretionary interruptions.

\subsubsection{Non-firm Transmission Transactions:}

These transactions are considered as; it may be curtail able or as-available basis. Curtailed transactions are referred as ongoing transactions. It may be curtailed at the utility's discretion. As-available transactions are referred as short term, mainly economy and these transactions that take place when transmission capacity becomes available at specific areas of the system at specific times.

\subsubsection{Long-term Transmission Transactions:}

Long term transmission transactions means it takes place over a long period spanning several years. The duration period of a long-term transmission transaction is generally long enough to allow building new transmission facilities. This long-term wheeling transaction is the result of contractual agreements distinguishes between the utility and wheeling customers. Example of this transaction is transmission service provided as part of long term firm power sales.

\subsubsection{Short -Term Transmission Transactions:}

These short-term transmission transactions may be considered as short as a few hours to as long as one or two years only. It does not associated with transmission reinforcements and it comes under the pooling arrangement or bilateral contract.

\subsection{Cost Component of Transmission System}

Transmission cost has gained important economics scale in power industry and they are reflected in the investment cost of transmission line, transformer and substation.

The various cost component involved in transmission system are listed as follows [23,24]:

1.2.1 Operating Cost

This is the cost which includes variable cost primarily to generation rescheduling and re dispatches to reduce the system losses, maintaining system voltage profile, reactive power support and line flow limits.

\subsubsection{Opportunity Cost}

It is defined as the cost which a transmission company has to foregoes to meet the transaction such as it could not use cheaper generation and could not realize revenue from firm contract due to line flow reactive limits.

1.2.4 Reliability cost

It is defined as each transmission transaction may change the service reliability level and expected outage cost and hence results in reliability cost. It is very difficult to assess as they attributed to the many factors such as in the timing, the duration, the customer location and the extent of service outage e.t.c.

\subsubsection{Reinforcement Cost}

This cost is charged to only for firm transactions and include capital cost of new transmission facilities needed to accommodate the transaction and also include the installation of additional reactive power resources to support the transaction.

\subsubsection{Existing Cost}

This existing cost includes the capital cost of the existing facilities used by the transmission transaction.

Therefore the establishment of transmission pricing should be computed such that the total transmission charge include the cost of all the fore mentioned component and thus make a small require amount of profit to the owner.

\section{Proposed Methodology}

Tracing method was proposed by J.Bialek in 1996 and it is based on ac power flow methods aiming to evaluate the contribution of transmission users to transmission usage. Bialek's method concept is defined as tracing the flows of electricity through power network and could be used for transmission pricing and recovering fixed transmission cost [25].

In this method, it is assumed that the nodal inflows are shared proportionally among nodal outflows. It uses the proportional sharing principle which states that for in any bus there are lines that inject power and other evacuate power. It allows quantifying how much of active or reactive power flow from a particular source to a specific load and also used to calculate the contribution of the generators and loads to the transmission line flows. 
In this method, the proportional sharing principle is used to trace the power flow of electricity. There are two basic algorithms used in this method are: Upstream algorithm and downstream algorithm and the algorithm assumes a lossless system in transmission network branch.

Downstream algorithm: In this algorithm, the power flow tracing are takes place from the generator to the load. Here the transmission usage and supplement charge is allocated to individuals loads and losses are allocated to generators. Upstream algorithm: In this algorithm, the power flow tracing takes place from a load to generator. Here the transmission usage and supplement charge is allocated to individual generators and losses are allocated to the load. This method can deal with both dc-power flow and ac power flows; that is, it can be used to find contributions of both active and reactive power flows.

Basically the algorithm is developed using a matrix formulation and it enables the use of linear algebra to analyze the numerical properties of the algorithm. It can also give solution to the questions as how much of the power delivered from a particular load or otherwise how much of the requirement of a particular load comes from a particular generator. The topological distribution factors are always considered as positive, because of this it eliminates the many problems associated with counter flows. Some minor drawbacks may be incurred in this method, only when the lines are heavily loaded due to the assumptions avail in problem formulation [26,27].

The power injections in each bus of the system are given by:

$$
\boldsymbol{P}_{i}=\sum_{j \in \alpha_{i}(u)}\left|\boldsymbol{P}_{i-j}\right|+\boldsymbol{P}_{G i} \quad \forall i=1,2, \ldots, n
$$

where $P_{i}$ is the total flow through bus $i, \alpha_{i}{ }^{(u)}$ is the set of buses that directly supply bus $i$ (the flow must go from other buses to bus $i$ ),

$P_{G i}$ is the generation in bus $i$ and

$P_{i-j}$ is the flow in line $j-i$, where

$\left|\boldsymbol{P}_{i-j}\right|=\left|\boldsymbol{P}_{j-1}\right|$

Using the proportionality principle, the flow in a line can be written as

$\left|\mathbf{P}_{\mathbf{i}-\mathbf{j}}\right|=\mathbf{c}_{\mathbf{j i}} ; \mathbf{P}_{\mathbf{j}}$, where $\left|\mathbf{C g}_{\mathbf{j i}}=\mathbf{P}_{\mathbf{i}-\mathbf{j}}\right| \mathbf{P}_{\mathbf{j}}$

Substituting the equation (2) in equation (1) and arrange it. The equation becomes

$$
\begin{gathered}
\boldsymbol{P}_{i}=\sum_{j \in \alpha_{i}(u)} \boldsymbol{C}_{j i} \cdot \boldsymbol{P}_{j}+\boldsymbol{P}_{G i} \quad \forall i=1,2, \ldots, n \\
\boldsymbol{P}_{i}-\sum_{j \in \alpha_{i}(u)} C_{j i} \cdot P_{j}=P_{G i} \quad o \quad A_{u} P=P_{G}
\end{gathered}
$$

where $A_{u}$ is an $(\mathrm{n} \times \mathrm{n})$ distribution matrix per injected powers, $P$ is the vector of bus flows and $P_{G}$ is the vector of bus generations.

The elements of matrix $\mathrm{A}_{\mathrm{u}}$ are defined as follow:

$$
\left[A_{u}\right]_{i j}= \begin{cases}1 & \text { for } i=j \\ -C_{i j}=\frac{-\left|P_{j-i}\right|}{P_{j}} & \text { for } j \in \alpha_{i}{ }^{(u)} \\ 0 & \text { e.o.c }\end{cases}
$$

where $j$ must be a bus that supplies power to $i$.

If $A_{u}^{-1}$ exists, then vector $P=A_{u}^{-1} \cdot P_{G}$ and its elements are given by:

$$
P_{i}=\sum_{k=1}^{n}\left[A_{u}{ }^{-1}\right]_{j k} \cdot P_{G k} \quad \text { for } i=1,2 \ldots, n
$$

The equation (6) represents the contribution from generator $k$ to bus $i$ is equal to $\left[A_{u}^{-1}\right\rfloor_{j k} \cdot P_{G k}$. A withdrawal of power in line $i$-1 from bus $i$ can be calculated as:

$$
\left|\boldsymbol{P}_{i-l}\right|=\frac{\left|\boldsymbol{P}_{i-l}\right|}{\boldsymbol{P}_{i}} . \boldsymbol{P}_{i}=\frac{\left|\boldsymbol{P}_{i-l}\right|}{\boldsymbol{P}_{i}} \sum_{k=1}^{n}\left[A_{u}^{-1}\right]_{j k} \cdot \boldsymbol{P}_{G k} .
$$




$$
=\sum_{k=1}^{n} D^{G} i-l, k . P_{G K} \quad \text { for } l \in \alpha_{i}^{(d)}
$$

where $\alpha_{i}^{(u)}$ is the set of buses directly supplied by bus $i$ and $D^{G} i-l, k=\frac{\left|P_{i-l}\right| \cdot\left[A_{u}^{-1}\right]_{j k}}{P_{i}}$ is a topological generation distribution factor, indicating the proportion of power that generator Contributes to line $i-l$.

These $D$ factors are the ones that permit to allocate the actual use of the transmission lines.

\section{Structure And Operation of IPFC}

In general, the simplest Inter line power flow controller consists of two back- to-backs DC to AC (VSC1 and VSC2) converters, which can be used to address the series compensation of the line or in other form; the IPFC has a number of SSSC devices. It is connected in series with coupling transformer of two transmission lines and the dc terminals of another converter are connected through a common dc link. The function of series converter associated with the support system controls the DC voltage across the capacitor and the reactive power voltage magnitude. The shunt converter has the capability to controls both the real power and reactive power voltage magnitude in within the limits position. The series reactive compensation is done by; the converters are connected to the common DC link to exchange active power $[28,29]$. The schematic diagram of IPFC is shown in Fig.1.

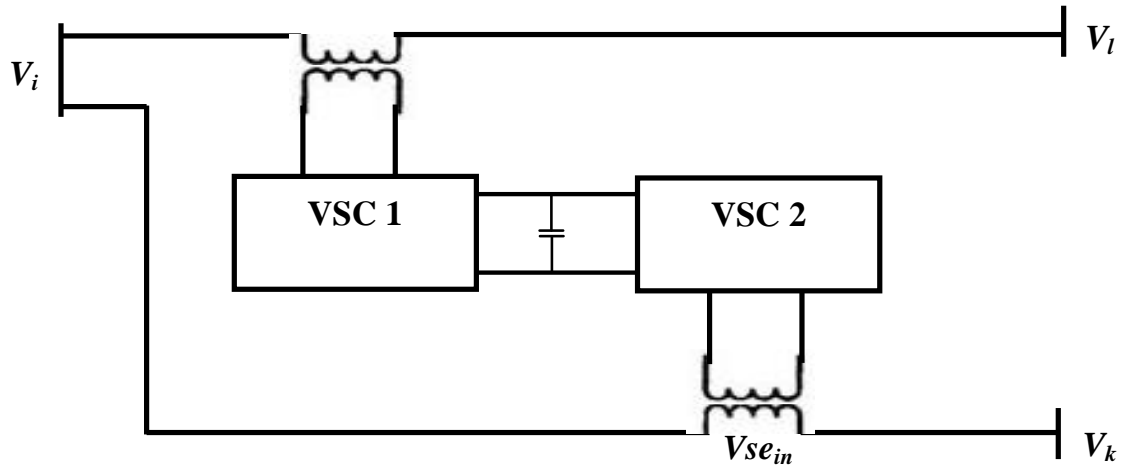

Fig 1. Schematic diagram of IPFC

The attractive features of IPFC offers the numerous advantages: Increasing the effectiveness of the overall compensating system for dynamic disturbance, independently controllable series compensation, direct transfer of real and reactive power between the compensated lines, reduce the resistive line voltage drops, transfer power demands from over loaded to under loaded lines, balancing both the real and reactive power flow in a multi-line system reducing the line power losses and improving the voltage profile [30,31]. The IPFC has the capability where the injected voltage in the line is controlled by exchange the real power to the series converter.

In this paper, the proposed Bialek's tracing method is combined with Interline power flow controller (IPFC) to obtain the minimized losses with the reduction of wheeling charges of various transactions. The algorithm of the proposed method is given below:

\section{Algorithm for Bialek's method}

Step 1: Read the Input line data, Bus data and Generator data of the proposed system.

Step 2: Run the AC power flow to analyze the base case studies.

Step 3: Evaluate the base power flows of each lines, from the base case studies

Step 4: Read the line lengths in miles of the system.

Step 5: Evaluate the tracing of line flow for each line with Bialek's method and find the new power flow by installing with and without IPFC.

Step 6: Calculate the real power and reactive power losses.

Step7: Determine the total cost of all transactions (TC).

$$
\mathrm{TC}=\frac{\text { total transmission cost of each generator }}{\text { total transmission cost of all generator }}
$$

Step 8: Compute the wheeling charge of each transactions.

$\mathrm{TCt}=\mathrm{TC} \times \frac{\text { each transaction cost }}{\text { power generation of generators }}$ 


\section{Results And Discussions}

The proposed Bialek's tracing method has been fused with IPFC controller and tested on a standard IEEE 30 bus test system using computer with Pentium-4, Intel Dual core $2.25 \mathrm{GHz}, 2 \mathrm{~GB}-\mathrm{RAM}$ and simulated in MATLAB 10.0 platform. In order to show the supreme performance of the proposed method, an attempt has been made to test the system on Standard IEEE 30 bus system. The system comprises 6 generating units with total demand of 1200MW. The transmission network includes 30 buses linked by 41 transmission lines with 4 tap changing transformers. The system configuration data can be found from ref [32] and the one line diagram is shown in figure 2.

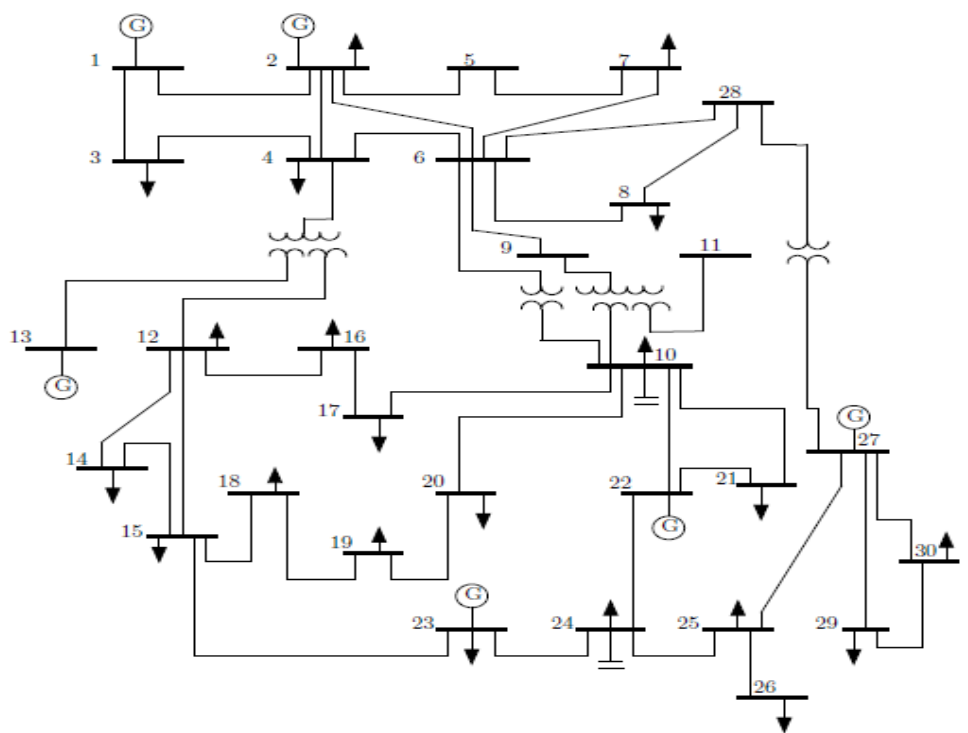

Figure 2: One line diagram of IEEE 30 bus system

\section{Simulation Results}

\section{Case 1: Simulation Results of IEEE 30 Bus Test Systems without FACTS Devices}

Table 1 depicts the base case power flow of the network with two different approaches, i.e with/without FACTS (IPFC). In the first case, the IPFC devices are not considered for the purpose, because the equality and inequality constraints are not considered. It can be seen that the base case power flow increase in most of the cases. In order to calculate the line flows and flows caused by each transaction, AC load flow analysis has been carried out. By satisfying the transmission constraints and implementing the IPFC in the system, the power flows follow a linear change. It is proved that the wheeling charges have been minimized after installing the FACTS devices in the considered test system.

The simulation results of Line-wise wheeling cost are displayed in Table 2. The wheeling charges have been calculated by considering the network capacity and sum of actual power flows. The simulation results of line cost, actual power flow for six different transactions are displayed in Table 3.

\section{Case 2: Simulation Results of IEEE 30 Bus Test Systems with FACTS Devices}

In this case, the performance of the proposed method has been improved by installing IPFC devices. The IPFC devices are placed in the buses which has the poor voltage profile. The IPFC has the capacity to control the power flow in multi transmission lines. The IPFC devices are introduced in the buses 5, 17, 21 and 25 , so as to reduce the wheeling charges for the corresponding transaction with minimizing active and reactive power losses. After the placement of IPFC devices in the above mentioned buses, the overall line reactance values are correspondingly reduced. From the simulation, it is observed that the base case power flow shows a linear change and it is better when compared that of results obtained from system without IPFC. The simulation results of line cost, actual power flow for six different transactions are displayed in Table 4.

Table 5,depicts the active power and reactive power losses of with/ without IPFC devices. Table 6 represents the simulation results of active and reactive power losses due to various transactions are compared and graphically represented in figure 3 .

The simulations results of wheeling charges for various transactions are compared and reported in Table 7.The graph shown in figure 4 illustrates the difference in transmission charges due to the placement of IPFC. From the above observations it is deserved that the proposed methodology provides significant reduction in transmission charges by the installation of FACTS devices. 
Performance Analysis of Wheeling Charges Determination Using Bialek's Tracing Method ..

Table 1: Base case power flow of with/without IPFC

\begin{tabular}{|c|c|c|}
\hline Line No & Base case flow Without IPFC & Base case flow With IPFC \\
\hline $2-1$ & 90.65 & 87.68 \\
\hline $1-3$ & 34.26 & 26.48 \\
\hline $2-4$ & 2.26 & 1.98 \\
\hline $2-5$ & 8.71 & 8.02 \\
\hline $2-6$ & 16.84 & 15.78 \\
\hline $3-4$ & 15.43 & 14.28 \\
\hline $4-6$ & 54.43 & 50.65 \\
\hline 4-12 & 23.16 & 22.11 \\
\hline $5-7$ & 42.68 & 39.78 \\
\hline $6-7$ & 0.56 & 0.46 \\
\hline $6-8$ & 3.78 & 2.92 \\
\hline $6-9$ & 21.90 & 20.14 \\
\hline $6-10$ & 98.65 & 85.72 \\
\hline $6-28$ & 0.43 & 0.36 \\
\hline $8-28$ & 7.89 & 6.68 \\
\hline $9-10$ & 43.67 & 42.17 \\
\hline $9-11$ & 65.98 & 62.56 \\
\hline $10-17$ & 76.22 & 74.18 \\
\hline $10-20$ & 14.55 & 10.23 \\
\hline $10-21$ & 12.98 & 6.76 \\
\hline $10-22$ & 55.26 & 29.96 \\
\hline $12-13$ & 9.91 & 8.78 \\
\hline $12-14$ & 0.87 & 0.54 \\
\hline $12-15$ & 31.45 & 29.78 \\
\hline $12-16$ & 66.54 & 62.23 \\
\hline 14-15 & 25.90 & 23.65 \\
\hline $15-18$ & 11.66 & 9.96 \\
\hline $15-23$ & 7.87 & 6.81 \\
\hline $16-17$ & 34.77 & 32.62 \\
\hline 18-19 & 89.32 & 87.34 \\
\hline $19-20$ & 80.67 & 72.34 \\
\hline $21-22$ & 50.78 & 47.89 \\
\hline $22-24$ & 42.78 & 40.65 \\
\hline $23-24$ & 12.81 & 10.86 \\
\hline $24-25$ & 0.96 & 0.65 \\
\hline $25-26$ & 52.89 & 48.90 \\
\hline $25-27$ & 22.88 & 18.86 \\
\hline $28-27$ & 91.67 & 89.44 \\
\hline $27-29$ & 68.90 & 66.78 \\
\hline $27-30$ & 76.65 & 74.23 \\
\hline $30-29$ & 80.22 & 79.14 \\
\hline
\end{tabular}

Table 2: Results of Line-wise wheeling cost of with /without IPFC

\begin{tabular}{|c|c|c|}
\hline Line No & Wheeling cost without IPFC & Wheeling cost with IPFC \\
\hline $2-1$ & 10002.12 & 9876.43 \\
\hline $1-3$ & 11445.43 & 2765.12 \\
\hline $2-4$ & 5678.09 & 2089.67 \\
\hline $2-5$ & 3342.22 & 9275.02 \\
\hline $2-6$ & 9876.08 & 6543.7 \\
\hline $3-4$ & 7223.12 & 0 \\
\hline $4-6$ & 0 & 2100.23 \\
\hline $4-12$ & 2113.45 & 2332.65 \\
\hline $5-7$ & 2587.90 & 3167.56 \\
\hline $6-7$ & 4200.19 & 0 \\
\hline $6-8$ & 0 & 189.56 \\
\hline $6-9$ & 216.75 & 597.12 \\
\hline $6-10$ & 661.22 & 0 \\
\hline $6-28$ & 0 & 2208.23 \\
\hline $8-28$ & 2654.13 & 3106.89 \\
\hline $9-10$ & 3110.32 & 1244.56 \\
\hline $9-11$ & 1663.64 & 939.75 \\
\hline $10-17$ & 941.01 & 526.45 \\
\hline $10-20$ & 800.32 & 789.01 \\
\hline $10-21$ & 800.32 & 345.85 \\
\hline $10-22$ & 365.34 & 600.62 \\
\hline $12-13$ & 626.62 & 2208.6 \\
\hline $12-14$ & 2109.87 & \\
\hline & & \\
\hline
\end{tabular}


Performance Analysis of Wheeling Charges Determination Using Bialek's Tracing Method ..

\begin{tabular}{|c|c|c|}
\hline & 412.56 & 408.45 \\
\hline $12-15$ & 1342.14 & 1265.67 \\
\hline $12-16$ & 1234.67 & 39.88 \\
\hline $14-15$ & 46.87 & 1498.2 \\
\hline $15-18$ & 1598.43 & 1888.6 \\
\hline $15-23$ & 1988.21 & 555.1 \\
\hline $16-17$ & 556.89 & 453.87 \\
\hline $18-19$ & 544.34 & 1989.2 \\
\hline $21-22$ & 2900.30 & 1205.6 \\
\hline $22-24$ & 1245.50 & 276.78 \\
\hline $23-24$ & 289.45 & 4278.4 \\
\hline $24-25$ & 4678.54 & 6766.9 \\
\hline $25-26$ & 6786.0 & 2188.4 \\
\hline $25-27$ & 2223.4 & 0 \\
\hline $28-27$ & 0 & 678.9 \\
\hline $27-29$ & 992.34 & 0 \\
\hline $30-29$ & 0 & 470.68 \\
\hline $29-30$ & 472.87 & 220.70 \\
\hline
\end{tabular}

Table 3 :Power Flow Results of IEEE 30 Bus System Without FACTS

\begin{tabular}{|c|c|c|c|c|c|c|c|}
\hline & & & Po & ow Due t & ious Trans & ions & \\
\hline Line No & Line cost & T1 & T2 & T3 & T4 & T5 & T6 \\
\hline $2-1$ & 11560 & 28.876 & 54.39 & 50.291 & 60.751 & 24.186 & 29.986 \\
\hline $1-3$ & 5780 & 104.07 & 98.346 & 76.01 & 99.526 & 12.425 & 58.462 \\
\hline $2-4$ & 9830 & 96.46 & 108.12 & 57.62 & 0 & 21.129 & 47.228 \\
\hline $2-5$ & 4860 & 185.69 & 188.52 & 33.243 & 88.087 & 27.295 & 28.019 \\
\hline $2-6$ & 2170 & 98.25 & 139.98 & 92.56 & 154.38 & 66.516 & 69.56 \\
\hline $3-4$ & 2890 & 0 & 219.91 & 294.31 & 117.48 & 58.128 & 229.78 \\
\hline $4-6$ & 4630 & 57.89 & 0 & 89.176 & 384.10 & 0 & 0 \\
\hline $4-12$ & 1230 & 53.46 & 82.624 & 42.263 & 72.666 & 18.978 & 79.451 \\
\hline $5-7$ & 21300 & 38.74 & 73.824 & 47.485 & 0 & 69.420 & 39.896 \\
\hline $6-7$ & 2020 & 70.85 & 46.691 & 45.015 & 68.757 & 93.45 & 40.286 \\
\hline $6-8$ & 3460 & 76.36 & 24.88 & 48.726 & 42.926 & 42.678 & 0 \\
\hline $6-9$ & 2430 & 95.418 & 66.046 & 79.150 & 0 & 64.153 & 70.120 \\
\hline $6-10$ & 1450 & 0 & 69.325 & 0 & 38.6 & 76.261 & 0 \\
\hline $6-28$ & 6780 & 89.140 & 0 & 0 & 66.621 & 87.780 & 65.067 \\
\hline $8-28$ & 2450 & 98.126 & 95.367 & 88.264 & 59.023 & 29.542 & 80.662 \\
\hline $9-10$ & 3740 & 69.391 & 92.279 & 17.510 & 0 & 34.022 & 18.258 \\
\hline $9-11$ & 4050 & 92.782 & 84.84 & 169.56 & 92.157 & 182.56 & 0 \\
\hline $10-17$ & 2860 & 68.360 & 0 & 0 & 0 & 14.67 & 152.6 \\
\hline $10-20$ & 2920 & 0 & 86.16 & 27.175 & 86.41 & 69.67 & 17.875 \\
\hline $10-21$ & 3120 & 77.261 & 19.26 & 59.872 & 0 & 86.96 & 47.867 \\
\hline $10-22$ & 6680 & 78.327 & 14.123 & 169.25 & 19.542 & 179.28 & 149.23 \\
\hline $12-13$ & 8710 & 56.282 & 0 & 0 & 37.077 & 0 & 28.186 \\
\hline $12-14$ & 9840 & 99.486 & 223.53 & 37.695 & 186.28 & 0 & 32.019 \\
\hline $12-15$ & 1980 & 99.45 & 69.27 & 89.817 & 21.109 & 77.82 & 0 \\
\hline $12-16$ & 4460 & 42.328 & 125.98 & 13.29 & 59.67 & 13.98 & 67.184 \\
\hline $14-15$ & 1200 & 68.853 & 79.624 & 61.95 & 45.726 & 17.67 & 0 \\
\hline $15-18$ & 5780 & 52.826 & 65.518 & 59.69 & 88.46 & 96.18 & 182.48 \\
\hline $15-23$ & 5690 & 96.724 & 64.326 & 23.243 & 93.657 & 51.823 & 19.826 \\
\hline $16-17$ & 2230 & 89.616 & 12.472 & 77.656 & 179.28 & 19.976 & 126.81 \\
\hline 18-19 & 3400 & 62.420 & 41.697 & 293.30 & 0 & 82.624 & 38.13 \\
\hline $19-20$ & 5690 & 0 & 0 & 0 & 177.56 & 0 & 76.29 \\
\hline $21-22$ & 1340 & 29.76 & 23.45 & 88.27 & 229.13 & 22.196 & 33.546 \\
\hline $22-24$ & 9780 & 58.128 & 69.85 & 46.543 & 77.67 & 29.824 & 22.876 \\
\hline $23-24$ & 4860 & 36.098 & 43.39 & 36.584 & 68.758 & 46.126 & 59.210 \\
\hline $24-25$ & 7980 & 34.75 & 74.36 & 43.005 & 0 & 222.50 & 68.756 \\
\hline $25-26$ & 2500 & 340.74 & 93.12 & 47.716 & 37.926 & 47.81 & 97.128 \\
\hline $25-27$ & 3450 & 320.04 & 172.45 & 68.104 & 44.18 & 66.67 & 0 \\
\hline $27-28$ & 2430 & 54.38 & 288.67 & 77.624 & 0 & 29.30 & 0 \\
\hline $27-29$ & 1680 & 68.66 & 66.508 & 86.20 & 64.271 & 0 & 34.38 \\
\hline $27-30$ & 2940 & 88.81 & 38.295 & 0 & 86.016 & 27.546 & 28.67 \\
\hline $30-29$ & 5780 & 52.78 & 14.298 & 149.56 & 89.914 & 33.876 & 18.128 \\
\hline \multicolumn{2}{|c|}{ Wheeling charges (\$) } & 2954.20 & 2142.7 & 3213.77 & 2826.513 & 3568.626 & 1865.20 \\
\hline
\end{tabular}


Performance Analysis of Wheeling Charges Determination Using Bialek's Tracing Method ..

Table 4: Power Flow Results of IEEE 30 Bus System With FACTS

\begin{tabular}{|c|c|c|c|c|c|c|c|}
\hline \multirow[b]{2}{*}{ Line No } & \multirow[b]{2}{*}{ Line cost } & \multicolumn{6}{|c|}{ Power Flow Due to Various Transactions } \\
\hline & & T1 & T2 & T3 & T4 & T5 & T6 \\
\hline $2-1$ & 11560 & 18.876 & 44.39 & 30.291 & 40.751 & 14.186 & 9.986 \\
\hline $1-3$ & 5780 & 99.07 & 88.346 & 72.01 & 97.526 & 11.425 & 48.462 \\
\hline $2-4$ & 9830 & 92.46 & 98.12 & 54.62 & 0 & 20.129 & 41.228 \\
\hline $2-5$ & 4860 & 183.69 & 182.52 & 30.243 & 80.087 & 26.295 & 18.019 \\
\hline $2-6$ & 2170 & 94.25 & 138.98 & 91.56 & 152.38 & 65.516 & 66.56 \\
\hline $3-4$ & 2890 & 0 & 216.91 & 290.31 & 110.48 & 48.128 & 220.78 \\
\hline $4-6$ & 4630 & 52.89 & 0 & 88.176 & 364.10 & 0 & 0 \\
\hline 4-12 & 1230 & 48.46 & 81.624 & 41.263 & 70.666 & 8.978 & 75.451 \\
\hline $5-7$ & 21300 & 36.74 & 72.824 & 42.485 & 0 & 59.420 & 36.896 \\
\hline $6-7$ & 2020 & 69.85 & 44.691 & 46.015 & 58.757 & 83.45 & 30.286 \\
\hline $6-8$ & 3460 & 73.36 & 28.88 & 44.726 & 22.926 & 40.678 & 0 \\
\hline $6-9$ & 2430 & 93.418 & 62.046 & 78.150 & 0 & 62.153 & 40.120 \\
\hline $6-10$ & 1450 & 0 & 67.325 & 0 & 28.6 & 72.261 & 0 \\
\hline $6-28$ & 6780 & 79.140 & 0 & 0 & 56.621 & 81.780 & 45.067 \\
\hline $8-28$ & 2450 & 88.126 & 90.367 & 80.264 & 58.023 & 19.542 & 70.662 \\
\hline $9-10$ & 3740 & 67.391 & 91.279 & 11.510 & 0 & 32.022 & 8.258 \\
\hline $9-11$ & 4050 & 82.782 & 83.84 & 160.56 & 82.157 & 180.56 & 0 \\
\hline $10-17$ & 2860 & 65.360 & 0 & 0 & 0 & 12.67 & 132.6 \\
\hline $10-20$ & 2920 & 0 & 83.16 & 20.175 & 76.41 & 68.67 & 12.875 \\
\hline $10-21$ & 3120 & 75.261 & 17.26 & 52.872 & 0 & 84.96 & 42.867 \\
\hline $10-22$ & 6680 & 68.327 & 10.123 & 162.25 & 9.542 & 178.28 & 140.23 \\
\hline $12-13$ & 8710 & 46.282 & 0 & 0 & 36.077 & 0 & 24.186 \\
\hline $12-14$ & 9840 & 97.486 & 220.53 & 32.695 & 184.28 & 0 & 20.019 \\
\hline $12-15$ & 1980 & 89.45 & 67.27 & 86.817 & 20.109 & 75.82 & 0 \\
\hline $12-16$ & 4460 & 40.328 & 124.98 & 12.29 & 58.67 & 12.98 & 64.184 \\
\hline 14-15 & 1200 & 66.853 & 78.624 & 51.95 & 40.726 & 13.67 & 0 \\
\hline $15-18$ & 5780 & 50.826 & 63.518 & 54.69 & 84.46 & 86.18 & 162.48 \\
\hline $15-23$ & 5690 & 93.724 & 60.326 & 20.243 & 83.657 & 41.823 & 15.826 \\
\hline $16-17$ & 2230 & 88.616 & 10.472 & 72.656 & 170.28 & 17.976 & 116.81 \\
\hline 18-19 & 3400 & 60.420 & 40.697 & 290.30 & 0 & 72.624 & 28.13 \\
\hline $19-20$ & 5690 & 0 & 0 & 0 & 171.56 & 0 & 74.29 \\
\hline $21-22$ & 1340 & 28.76 & 22.45 & 86.27 & 228.13 & 12.196 & 23.546 \\
\hline $22-24$ & 9780 & 48.128 & 67.85 & 41.543 & 75.67 & 25.824 & 12.876 \\
\hline $23-24$ & 4860 & 26.098 & 41.39 & 33.584 & 65.758 & 16.126 & 57.210 \\
\hline $24-25$ & 7980 & 33.75 & 72.36 & 42.005 & 0 & 220.50 & 58.756 \\
\hline $25-26$ & 2500 & 240.74 & 90.12 & 45.716 & 34.926 & 45.81 & 87.128 \\
\hline $25-27$ & 3450 & 220.04 & 170.45 & 64.104 & 34.18 & 64.67 & 0 \\
\hline $27-28$ & 2430 & 44.38 & 258.67 & 74.624 & 0 & 28.30 & 0 \\
\hline $27-29$ & 1680 & 62.66 & 65.508 & 85.20 & 54.271 & 0 & 14.38 \\
\hline $27-30$ & 2940 & 86.81 & 28.295 & 0 & 56.016 & 20.546 & 18.67 \\
\hline $30-29$ & 5780 & 50.78 & 12.298 & 146.56 & 87.914 & 13.876 & 12.128 \\
\hline \multicolumn{2}{|c|}{ Wheeling charges (\$) } & 2865.582 & 2998.493 & 2638.727 & 2795.71 & 1940.024 & 1830.966 \\
\hline
\end{tabular}

Table 5 : Active power losses and Reactive power losses of with/ without FACTS

\begin{tabular}{|c|c|c|c|c|}
\hline \multirow{2}{*}{ Line No } & \multicolumn{2}{|c|}{ Active power loss } & \multicolumn{2}{c|}{ Reactive power loss } \\
\cline { 2 - 5 } & Without IPFC & With IPFC & Without IPFC & 0.2865 \\
\hline $2-1$ & 0.2865 & 0.2865 & 0.2865 & 0.1552 \\
\hline $1-3$ & 0.1782 & 0.1452 & 0.1782 & 0.1537 \\
\hline $2-4$ & 0.1637 & 0.1637 & 0.1637 & 0.2379 \\
\hline $2-5$ & 0.2279 & 0.2379 & 0.2379 & 0.0595 \\
\hline $2-6$ & $\mathbf{0 . 1 9 8 3}$ & $\mathbf{0 . 1 4 8 7}$ & $\mathbf{0 . 1 9 8 3}$ & 0.1763 \\
\hline $3-4$ & 0.1763 & 0.1763 & 0.1763 & 0.1160 \\
\hline $4-6$ & 0.0314 & 0.0314 & 0.0314 & 0.0820 \\
\hline $4-12$ & 0.1160 & 0.1160 & 0.1160 & 0.0420 \\
\hline $5-7$ & 0.0820 & 0.0820 & 0.0820 & 0.2080 \\
\hline $6-7$ & 0.0420 & 0.0420 & 0.0420 & 0.5560 \\
\hline $6-8$ & 0.2080 & 0.2080 & 0.2080 & 0.2080 \\
\hline $6-9$ & 0.5560 & 0.5560 & 0.5560 & 0.1100 \\
\hline $6-10$ & 0.2080 & 0.2080 & 0.2080 & 0.2560 \\
\hline $6-28$ & 0.1100 & 0.1100 & 0.1100 & 0.1400 \\
\hline $8-28$ & 0.2560 & 0.2560 & 0.2560 & $\mathbf{0 . 5 5 5 9}$ \\
\hline $9-10$ & 0.1400 & 0.1400 & 0.1400 & 0.1304 \\
\hline $9-11$ & $\mathbf{0 . 2 6 8 0}$ & $\mathbf{0 . 1 5 5 9}$ & $\mathbf{0 . 2 5 5 9}$ & 0.1987 \\
\hline $10-17$ & 0.1304 & 0.1304 & 0.1304 & 0.1997 \\
\hline $10-20$ & 0.1987 & 0.1987 & 0.1987 & $\mathbf{0 . 1 0 3 2}$ \\
\hline $10-21$ & 0.1997 & 0.1997 & 0.1997 & $\mathbf{0 . 2 4 3 2}$ \\
\hline $10-22$ & $\mathbf{0 . 2 6 3 2}$ & $\mathbf{0 . 1 6 3 2}$ & & \\
\hline
\end{tabular}


Performance Analysis of Wheeling Charges Determination Using Bialek's Tracing Method ..

\begin{tabular}{|l|l|l|l|l|}
\hline $12-13$ & 0.2185 & 0.2185 & 0.2185 & 0.2185 \\
\hline $12-14$ & 0.1292 & 0.1292 & 0.1292 & 0.1292 \\
\hline $12-15$ & 0.0680 & 0.0680 & 0.0680 & 0.0680 \\
\hline $12-16$ & $\mathbf{0 . 1 8 9 0}$ & $\mathbf{0 . 1 8 9 0}$ & $\mathbf{0 . 1 6 4 0}$ & $\mathbf{0 . 1 6 5 0}$ \\
\hline $14-15$ & 0.0845 & 0.0845 & 0.0845 & 0.0845 \\
\hline $15-18$ & 0.0749 & 0.0749 & 0.0749 & 0.0749 \\
\hline $15-23$ & 0.1499 & 0.1499 & 0.1499 & 0.0236 \\
\hline $16-17$ & 0.0236 & 0.0236 & 0.0236 & 0.2020 \\
\hline $18-19$ & 0.2020 & 0.2020 & 0.2020 & 0.1790 \\
\hline $19-20$ & 0.1790 & 0.1790 & 0.1790 & 0.2700 \\
\hline $21-22$ & 0.2700 & 0.2700 & 0.2700 & 0.3292 \\
\hline $22-24$ & 0.3292 & 0.3292 & 0.3292 & 0.3800 \\
\hline $23-24$ & 0.3800 & 0.3800 & 0.3800 & 0.2087 \\
\hline $24-25$ & 0.2087 & 0.2087 & 0.2087 & 0.3960 \\
\hline $25-26$ & 0.3960 & 0.3960 & 0.3960 & 0.4153 \\
\hline $25-27$ & 0.4153 & 0.4153 & 0.4153 & 0.6027 \\
\hline $28-27$ & 0.6027 & 0.6027 & 0.6027 & 0.5026 \\
\hline $27-29$ & 0.5026 & 0.5026 & 0.5026 & 0.3128 \\
\hline $27-30$ & 0.3128 & 0.3128 & 0.3128 & 0.2476 \\
\hline $30-29$ & 0.2476 & 0.2476 & 0.2476 & \\
\hline
\end{tabular}

Table 6: Comparison of Active power losses and reactive power losses of With/Without IPFC

\begin{tabular}{|c|c|c|}
\hline Transactions & Active power losses with IPFC & Reactive power losses with IPFC \\
\hline T1 & 90.65 & 86.86 \\
\hline T2 & 26.48 & 23.48 \\
\hline T3 & 1.98 & 5.76 \\
\hline T4 & 8.02 & 8.43 \\
\hline T5 & 16.84 & 16.95 \\
\hline T6 & 15.43 & 16.78 \\
\hline Total Losses & $\mathbf{1 5 9 . 4}$ & $\mathbf{1 5 8 . 2 6}$ \\
\hline
\end{tabular}

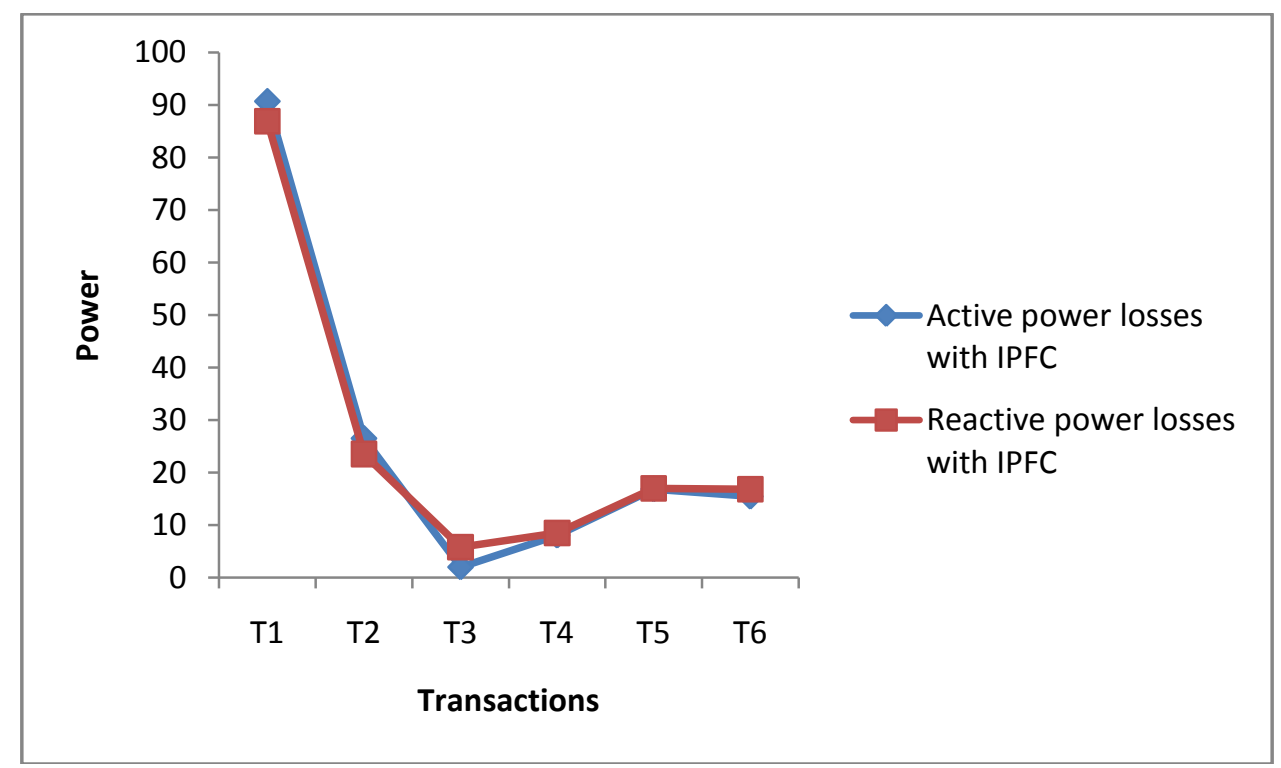

Fig. 3. Comparison of active power and reactive power losses with IPFC controller

Table 7: Comparison of wheeling charges of with/ Without IPFC

\begin{tabular}{|c|c|c|}
\hline Transactions & Without IPFC & With IPFC \\
\hline $\mathrm{T} 1$ & 2954.20 & 2865.582 \\
\hline $\mathrm{T} 2$ & 2142.7 & 2998.493 \\
\hline $\mathrm{T} 3$ & 3213.77 & 2638.727 \\
\hline $\mathrm{T} 4$ & 2826.513 & 2795.71 \\
\hline $\mathrm{T} 5$ & 3568.626 & 1940.024 \\
\hline $\mathrm{T} 6$ & 1865.20 & 1830.966 \\
\hline Total Wheeling Charges (\$) & $\mathbf{1 6 5 7 1 . 0 0 9}$ & $\mathbf{1 5 0 6 9 . 5 0 2}$ \\
\hline
\end{tabular}




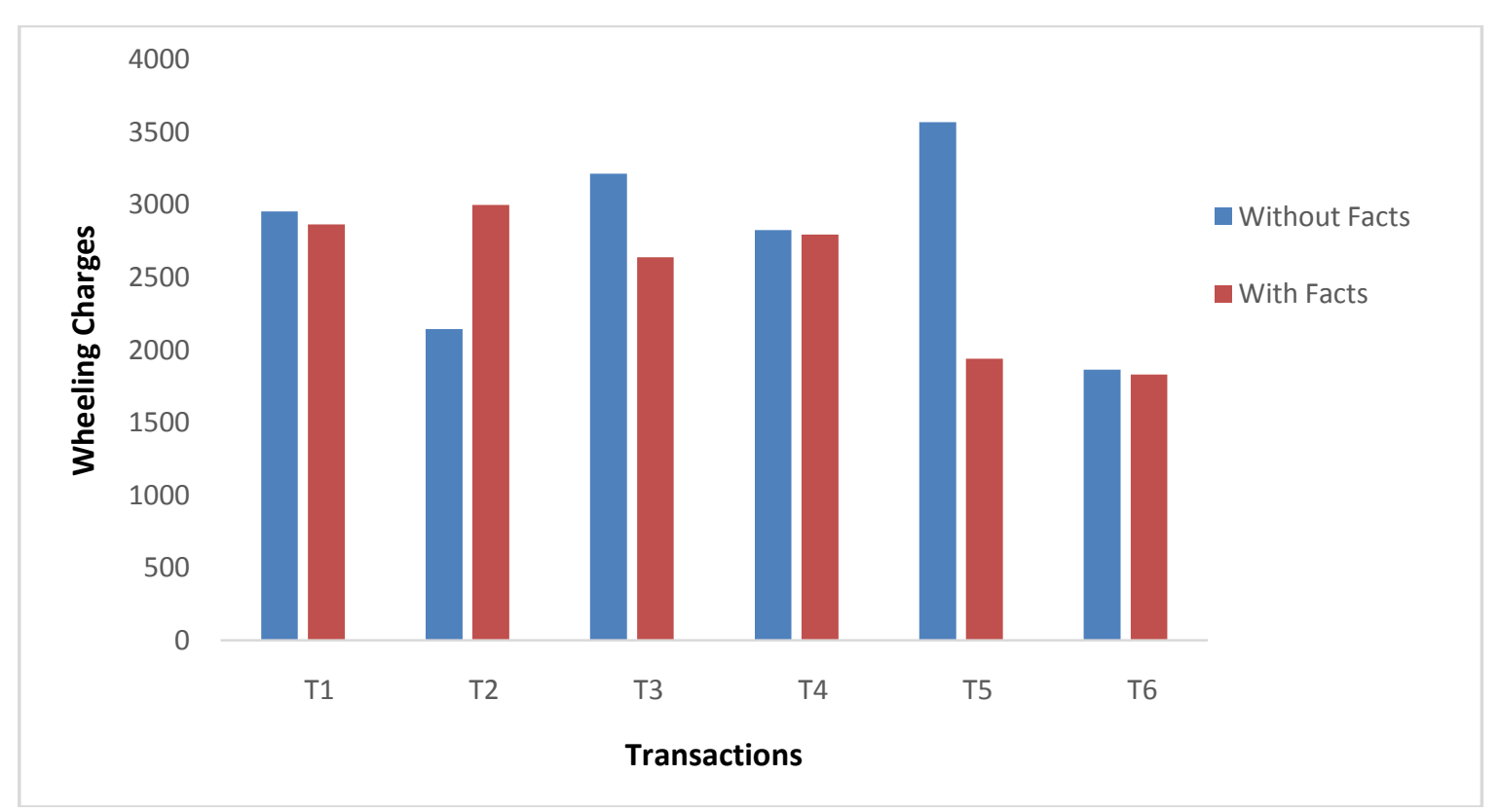

Fig. 4. Comparison of wheeling charges for various transactions for with/ without IPFC controller

\section{Conclusion}

In the present open access restructured power systems, it is obligatory to develop a fair transmission pricing tariff to trace the power flow. This article proposes a simple and understandable price structure of flow based Bialek's tracing method employed with IPFC controller to allocate the transmission wheeling cost to the consumers. The performance and applicability of the proposed approach has been analyzed on IEEE 30 bus test system. The Bialek's tracing method used in this work creates only positive contributions to the line flows and it provides zero charges for some users. Among the all pricing methods, Bialek's method is intuitive and it is the best way of transmission pricing among pricing methods. The multi control capability of IPFC introduces in this paper paves the important role in the allocation of transmission wheeling charges. More over it is demonstrated that the proposed method is accurate and feasible and the use of IPFC device can increase the power flow.

\section{Acknowledgements}

The authors gratefully acknowledge the authorities of Annamalai University for the facilities offered to carry out this work.

$\begin{array}{lll}P_{i} & - & \text { Total Flow Through bus i } \\ \alpha_{i}^{(u)} & - & \text { Set of Buses that Directly Supply Bus } \\ P_{G i} & - & \text { Generation in bus } i \\ P_{i-j} & - & \text { Flow in Line } j-i \\ A_{u} & - & (\mathrm{n} \times \mathrm{n}) \text { Distribution Matrix Per Injected Powers } \\ P & - & \text { Vector of Bus Flows } \\ P_{G} & - & \text { Vector of Bus Generations } \\ D^{G} & - & \text { Topological Generation Distribution Factor } \\ \text { FACTS } & - & \text { Flexible Alternating Current Transmission System } \\ \text { IPFC } & - & \text { Inter Line Power Flow Controller } \\ \text { SVC } & - & \text { Static Var Compensator } \\ \text { STATCOM } & - & \text { Static Synchronous Compensator } \\ \text { TCSC } & - & \text { Thyristor Controlled Series Capacitor } \\ \text { SSSC } & - & \text { Static Synchronous Series Compensator } \\ \text { TCPST } & - & \text { Thyristor Controlled Phase Shifting Transformer } \\ \text { UPFC } & - & \text { Unified Power Flow Controller } \\ \text { MVA } & - & \text { Mega Volt Ampere } \\ \text { VSC } & - & \text { Voltage Source Converter }\end{array}$




\section{Reference}

[1] Kankare Bhattacharya, Math H.J. Bollen and Jaap E. Daalder Operation of Restructured Power System, Kluwer Academic Publishers, 2001.

[2] Shirmohammadi, D., Filho, X.V., and Pereira, M.V.P., Transmission Pricing: Paradigms and methodologies, in 4 Symposium of Specialists in Electrical Operational and Expansion Planning, Brazil, paper IP , 1994, Vol. 36.

[3] Pan, J., Teklu, Y., andRahman, S. Review of Usage-Based Transmission cost Allocation Methods Under Open Access, IEEE Transaction Power System, Vol. 15(4), 2000, pp.1218-1224.

[4] D.Shirmohammadi, X.V.Filho, B.Gorenstin, and M.V.P.Pereira, "Some Fundamental Technical Concepts About Cost Based Transmission Pricing, "IEEE Transaction Power System., Vol.11, No.2, 1996, pp.1002-1008,.

[5] R.R. Kovacs and A.L. Leverett, "A Load flow based method for calculating embedded, incremental and marginal cost of transmission capacity,” IEEE Transactions power system, Vol. 9, No. 1, 1994, pp. 272-278,.

[6] J. D. Shirmohammadi, P. R Gribik, E. T. K. Law, J.,H. Malinowski and R. E. O Donnell, "Evaluation of Transmission Network Capacity Use for Wheeling Transactions”, IEEE Transactions on Power Systems, Vol. 4, 1989, pp.1405-1413,

[7] J.W.Marangon Lima, Allocation of Transmission Fixed Charges: An Overview, IEEE Transactions on Power Systems, Vol.11(3), 1996, pp 1409-1418.

[8] R.Gnanadass and N.P.Padhy, "A New Approach for Transmission Embedded Cost Allocation in Restructured Power Market”, Journal of Energy and Environment 4, 2005, pp. 37-47.

[9] Rudnic, H., Soto, M., and Palma, R. Use of system approaches for transmission open access pricing, International Journal of Electrical Power Energy System Vol. 21, 1999, pp. 125-135.

[10] Bialek Tracing the Flow of Electricity ,IEE Proceeding-Generation Transmission, Distribution, Vol.143(4), 1996, pp. 313-320.

[11] Kirschen, D., Allan, R., and Strbac, G. Contributions of Individual GeneratorstoLoadsandFlows,IEEE Transaction Power System, Vol. 12(1), 1997, pp. 52-60.

[12] Ferdinand Gubina, David Grgic and Ivo Bani, A Method for Determining the Generators' Share in a Consumer Load, IEEE transactions on power systems, 2000, Vol. 15(4).

[13] Antonio J. Conejo, Javier Contreras, Delberis A. Lima and Antonio Padilha-Feltrin ,Z-bus Transmission Network Cost Allocation, IEEE transactions on power systems, 2007, Vol. 22(1).

[14] Abhyankar, A.R., Soman, S.A., and Khaparde, S.A. Optimization Approach to Real Power Tracing: An Application to Transmission Fixed Cost Allocation, IEEE transactions on power systems, 2006, Vol. 21(3).

[15] Kaigui Xie, Jiaqi Zhou and Wenyuan Li Analytical model and algorithm for tracing active power flow based on extended incidence matrix Electric Power Systems Research, Vol. 79, 2008, pp. 399-405.

[16] Rao, M.S.S., Soman, S.A., Chitkara, P., Gajbhiye, R.K., Hemachandra, N., and Menezes, B.L. Min-Max Fair Power Flow Tracing for Transmission System Usage Cost Allocation: A Large System Perspective, IEEE Transactions on Power Systems , Vol. 25(3), 2010, pp. 1457-1468.

[17] Silva, E.L., Mesa, S.E.C., and Morozowski, M. Transmission access pricing to wheeling transactions: A reliability-based approach, IEEE Transaction of Power System Vol. 13, 1998pp. 1481-1486.

[18] Hingorani, N.H. , Flexible AC Transmission System, IEEE Spectrum, Vol. 30(4), 1993, pp. 40-45.

[19] Mathur, R.M., and Varma, R.K. Thyristor-based FACTS Controllers for Electrical Transmission Systems, IEEE Press, Wiley Inter Science Publication, Piscataway, 2002, USA.

[20] Xiao, Y., Song, Y.H., and Sun, Y.Z. Power flow control approach to power systems with embedded FACTS devices, IEEE Trans. Power Syst. Vol. 17(4), 2002, pp. 943-950.

[21] Padmaja Maddala, N.V.S.Sushmita, Impact of Optimally Placed TCSC on Transmission Pricing, Inernational Journal of Electrical and Electronics Engineering, 2016, Vol.8(1).

[22] D.Shirmohammadi, C.Rajagopalan, E.R.Alward and C.L.Thomas, "Cost of transmission transactions:An Introduction:, IEEE Transactions on Power systems, 1991, pp.1546-1556.

[23] R.A.Wakefield, J.S.Graves and F.Vojdani, "A Transmission services costing Framework”, IEEE Transactions on Power systems, 1997, Vol.12(2).

[24] Happ, H.H Cost of Wheeling Methodologies, IEEE Transactions power system, Vol.9(1) 1994, ,pp. 147-156.

[25] Bialek, J. Topological Generation and load Distribution Factors for Supplement Charge Allocation in Transmission Open Access, IEEE Transaction on Power Systems, Vol. 12(3), 1997, pp. 1185-1193.

[26] Bialek, J, Allocation of Transmission Supplementary Charge to Real and Reactive loads, IEEE Transaction Power System, Vol. 13(3), 1997, pp. 52-60.

[27] J.W. Bialek and P.A. Kattuman Propotional Sharing Assumption on Tracing Methodology, IEE Proceedings-Generation, Transmission and Distribution, Vol.151(4), 2004, pp 526-532.

[28] Gyugyi, L., Sen, K.K., and Schauder, C.D. The Interline Power Flow Controller Concept a New Approach to Power Flow Management in Transmission Systems, IEEE Transactions on. Power Delivery, Vol. 14(3), 1999, pp. 1115-1123.

[29] Teerathana, S., Yokoyama, A., Nakachi, Y., and Yasumatsu, M. An optimal power flow control method of power system by interline power flow controller (IPFC), In Proceedings of $7^{\text {th }}$ International. Power Engineering Conference, Singapore. 2005, pp. 1-6.

[30] Jun Zhang and Akihiko Yokoyama Optimal power flow for congestion management by interline power flow controller (IPFC), IEEE, International. Conference. on Power System Technology, Chongqing, China, 2006.

[31] De Olivera, E.J..W.Marangon Lima and J.I.R Pereira, Flexible AC Transmission Devices: Allocation and Transmission Pricing, Electrical Power and Energy Systems,Vol.21(2): 1999, pp.111-118.

[32] R.Gnanadass, N.P.Padhy and K.Manivannan," Assessment of available transfer capability for practical power systems with combined economic emission dispatch”, Electric Power Energy Systems Research, Vol.69, No.2-3, 2004, pp 267-276. 